\title{
Downregulation of mir-23b in plasma is associated with poor prognosis in patients with colorectal cancer
}

\author{
CHANG-HUA KOU $^{1 *}$, TIAN ZHOU $^{2 *}$, XI-LIN HAN $^{1}$, HUI-JIE ZHUANG ${ }^{1}$ and HAI-XIN QIAN ${ }^{3}$ \\ Departments of ${ }^{1}$ Oncological Surgery and ${ }^{2}$ Gastroenterology, The Central Hospital of Xuzhou, Xuzhou, \\ Jiangsu 221009; ${ }^{3}$ The First Affiliated Hospital of Soochow University, Suzhou, Jiangsu 215000, P.R. China
}

Received April 20,2015; Accepted September 12, 2016

DOI: $10.3892 / \mathrm{ol} .2016 .5265$

\begin{abstract}
MicroRNAs (miRNAs) are short, non-coding RNA molecules that act as regulators of gene expression. Circulating blood miRNAs have potential as cancer biomarkers. The main objective of the present study was to assess the effect of miRNA-23b (miR-23b) expression in plasma on the diagnosis and prognosis of colorectal cancer (CRC). Reverse transcription-quantitative polymerase chain reaction (PCR) was used to measure miR-23b expression levels, and methylation-specific PCR was used to test the promoter methylation status. Subsequently, the expression level of miR-23b in plasma samples was compared between CRC patients and healthy control individuals. The miR-23b expression levels were significantly lower in CRC cells and primary CRC tissues than in nonmalignant colorectal tissues $(\mathrm{P}<0.001)$. It was also shown that miR-23b expression is downregulated by promoter methylation and can be restored by demethylation agent treatment. miR-23b was significantly decreased in plasma samples from CRC patients compared with the healthy control individuals $(\mathrm{P}<0.001)$. The value of the area under the receiver operating characteristic curve was 0.842 (sensitivity, 84.38\%; specificity, $77.08 \%$; 95\% confidence interval, 0.763-0.922). Low plasma miR-23b expression was significantly associated with clinical stage, tumor depth, distant metastasis and tumor recurrence. CRC patients with low miR-23b expression in plasma exhibited a shorter recurrence-free survival time and poorer overall survival rate. The present results suggested that the downregulation of miR-23b in the plasma has the potential to be a diagnostic and prognostic biomarker in CRC.
\end{abstract}

Correspondence to: Dr Chang-Hua Kou, Department of Oncological Surgery, The Central Hospital of Xuzhou, 199 Jiefangnan Road, Xuzhou, Jiangsu 221009, P.R. China

E-mail: chkoukou@hotmail.com

*Contributed equally

Key words: miR-23b, colorectal cancer, plasma, methylation, diagnosis, prognosis

\section{Introduction}

Colorectal cancer (CRC) is one of the most frequently diagnosed cancers and is the fourth most common cancer diagnosed in males and the third in females (1). In China, CRC has become the fifth most common malignancy and its incidence has shown an evident increase over the previous decade (2). The majority of cases of CRC are diagnosed at an advanced stage of disease, due to inconvenient methods of current CRC screening tests. Colonoscopy has been promoted for the detection of malignant lesions, but the requirements of bowel preparation and the invasive nature of colonoscopy have impeded its widespread application as a screening tool (3). Therefore, there is a requirement for noninvasive biomarkers to supplement and advance current diagnostic and prognostic tools in CRC.

MicroRNAs (miRNAs) are small (23-25 nucleotides in length) endogenous non-coding RNAs that negatively regulate gene expression at the post-transcriptional level through RNA interference $(4,5)$. miRNAs are essential for various biological processes associated with carcinogenesis, such as proliferation, apoptosis, metastasis and differentiation (6-8). Previous studies have demonstrated that miRNAs are abnormally expressed in tumors and contribute to the initiation and progression of CRC as oncogenes or tumor suppressors (9-11). Furthermore, miRNAs can be detected in tissues and blood samples, which can be easily obtained from individuals. Mitchell et al (11) showed that miRNAs are present in human plasma in a stable form that is protected from endogenous RNase activity. Numerous studies have been focused on cancer-derived miRNAs in the circulation system from cancer patients (13-15), which suggests that plasma miRNAs are novel noninvasive biomarkers for the diagnosis and prognosis of cancers.

Among miRNAs, miRNA-23b (miR-23b) is a member of the miR-23b/27b/24 cluster (9q22.32) and has been described as an epigenetically silenced gene in prostate cancer (16). Functionally, overexpression of miR-23b significantly inhibited migration, proliferation, invasion and tumor growth (17-19). In accordance with its tumor suppressor role, miR-23b has been found to be downregulated in numerous cancers (20-24). However, data concerning the association between the expression of miR-23b in plasma and CRC were not reported yet. Therefore, to the best of our knowledge, the present study 
provides the first evidence for epigenetic regulation of $\mathrm{miR}-23 \mathrm{~b}$ in CRC, and the expression levels of miR-23b in the plasma of patients with CRC.

In the present study, the expression of miR-23b in CRC cell lines and paired CRC tissues was validated, and the methylation status of miR-23b in CRC cells was assessed. Subsequently, the expression levels of plasma miR-23b were evaluated in CRC patients and healthy individuals to determine whether there was an association between the expression of miR-23b and the clinical outcomes of CRC patients.

\section{Materials and methods}

Patients and samples. A total of 96 blood samples were obtained from patients that underwent tumor resection for CRC between January 2009 and February 2010 at the Departments of Oncological Surgery and Gastroenterology at the Central Hospital of Xuzhou (Xuzhou, China). All patients did not receive anticancer intervention, including chemotherapy or radiotherapy, prior to surgical resection. No participants had a history of cancer. For the control group, blood samples from 48 healthy individuals with no colonic disease were obtained at the hospital. The healthy individuals were matched to the CRC patients according to age and gender. In total, 20 tissue specimens (10 malignant tissues and 10 adjacent non-malignant tissues) were snap-frozen at the time of surgery and stored at $-80^{\circ} \mathrm{C}$ until use. All patient samples were checked microscopically for the presence of malignant tissue. Adjacent non-malignant samples were obtained from tissue that appeared morphologically normal. Clinicopathological data were collected from the medical records of patients. The tumor-node-metastasis (TNM) stage was assessed according to the criteria of the American Joint Committee on Cancer (25). The experimental protocol was approved by the Clinical Research Ethics Committee of the Central Hospital of Xuzhou, and written informed consent was obtained from all patients.

Cell culture and 5-aza-2-deoxycytidine (5-Aza) treatment. In total, 5 human colon cell lines, consisting of the LoVo, SW480, HCT-116, HT-29 and Caco-2 cell lines, were purchased from the American Type Culture Collection (Manassas, VA, USA) and were incubated in $5 \% \mathrm{CO}_{2}$ at $37^{\circ} \mathrm{C}$. LoVo cells were cultured in Ham's F12-K medium, SW480 cells were cultured in RPMI-1640 medium, Caco-2 cells were cultured in minimal essential medium, and HCT-116 cells and HT-29 cells were cultured in McCoy's 5A medium. All media were purchased from Sigma-Aldrich (Merck Millipore, Darmstadt, Germany) and supplemented with $10 \%$ fetal bovine serum (Thermo Fisher Scientific, Inc.). The demethylation treatment was performed with a commonly used concentration $(5 \mu \mathrm{M})$ of 5-Aza (Sigma-Aldrich; Merck Millipore). The fresh medium containing 5-Aza was changed every $24 \mathrm{~h}$ for 3 days and treated cells were harvested at $72 \mathrm{~h}$.

Plasma preparation and RNA extraction. Plasma samples were obtained by centrifuging the peripheral blood $(3 \mathrm{ml}$; collected in EDTA-K2 anti-coagulant tubes) at 1,400 x $g$ for $20 \mathrm{~min}$ and at $13,400 \times \mathrm{g}$ for $10 \mathrm{~min}$ at $4^{\circ} \mathrm{C}$. The plasma samples were aliquoted and stored in clean tubes at $-80^{\circ} \mathrm{C}$ for further analysis.

Total RNA (including miRNA) from tissues or cells or plasma samples was extracted using Qiagen miRNeasy Mini kit (Qiagen, Inc., Valencia, CA, USA) and Ribopure Blood RNA Isolation kit (Ambion; Thermo Fisher Scientific, Inc.), according to the manufacturer's instructions. The concentration and quality of the isolated RNA was assessed on a NanoDrop ND-1000 Spectrophotometer (NanoDrop, Wilmington, DE, USA). RNA samples were stored at $-80^{\circ} \mathrm{C}$ until use.

Reverse transcription-quantitative polymerase chain reaction $(R T-q P C R)$. miR-23b was reverse transcribed using the TaqMan Reverse Transcription kit (Applied Biosystems; Thermo Fisher Scientific, Inc.). RT-qPCR was performed using SYBR Green PCR Master Mix (Applied Biosystems; Thermo Fisher Scientific, Inc.) on an ABI 7300HT PCR system (Applied Biosystems; Thermo Fisher Scientific, Inc.). Reactions were performed in a total volume of $20 \mu \mathrm{l}$ consisting of $2 \mu \mathrm{l}$ template (200 ng), $10 \mu \mathrm{l}$ 2X SYBR Green Mix, $0.6 \mu 1200$ nM forward and reverse primers, and $6 \mu \mathrm{l}$ nuclease-free water. The primers were used as follows: 5'-GAGCATCACATTGCCAGGG-3' (mir-23b forward), 5'-GTGCAGGGTCCGAGGT-3' (mir-23b reverse), 5'-CTCGCTTCGGCAGCACATAT-3' (U6 forward) and 5'-TTGCGTGTCATCCTTGCG-3' (U6 reverse). All primers were purchased from Invitrogen; Thermo Fisher Scientific, Inc. (Waltham, MA, USA). The PCR conditions were as follows: Initial denaturation at $95^{\circ} \mathrm{C}$ for $5 \mathrm{~min}$, followed by 45 cycles of $95^{\circ} \mathrm{C}$ for $30 \mathrm{sec}, 56^{\circ} \mathrm{C}$ for $20 \mathrm{sec}$, and $72^{\circ} \mathrm{C}$ for $30 \mathrm{sec}$. RNU6B (U6) was used as an internal control. The relative expression levels of miR-23b were normalized to the internal control U6, and were calculated using the $2^{-\Delta \Delta C q}$ method $\left(\Delta \mathrm{Cq}=\mathrm{Cq}_{\text {miR-23b }}-\mathrm{Cq}_{\mathrm{U} 6}\right)$ (26). Each experiment was conducted in triplicate.

DNA extraction, bisulfite conversion and methylation-specific PCR (MSP). DNA was isolated from tissue samples and CRC cells using DNeasy Blood \& Tissue kit (Qiagen, Inc.). The extracted DNA was then subjected to bisulfite treatment, which was performed using the EpiTect Bisulfite kit (Qiagen, Inc.), according to the manufacturer's instructions. The amplification reaction was conducted under the following conditions: $95^{\circ} \mathrm{C}$ for $5 \mathrm{~min}$, then 46 cycles of $95^{\circ} \mathrm{C}$ for $45 \mathrm{sec}, 56^{\circ} \mathrm{C}$ for $35 \mathrm{sec}, 72^{\circ} \mathrm{C}$ for $50 \mathrm{sec}$, and finally $10 \mathrm{~min}$ at $72^{\circ} \mathrm{C}$. The PCR products were visualized on $2 \%$ agarose gels.

Statistical analysis. The SPSS 16.0 software (SPSS, Inc., Chicago, IL, USA) and Prism (GraphPad Software, La Jolla, CA, USA) was used to perform statistical analysis of results. The Wilcoxon $t$-test was used to compare the paired samples obtained from primary CRC tissues and adjacent non-cancerous colorectal tissues. The Mann-Whitney test was performed to compare the expression levels of miR-23b in plasma from CRC patients and healthy control individuals. The diagnostic performance of plasma miR-23b was assessed by receiver operating characteristic (ROC) curve analysis. The cut-off value (median of the expression level) was used to define the mir-23b expression status (low or high mir-23b). The association between the expression status of mir-23b and clinicopathological characteristics were determined by applying 
A
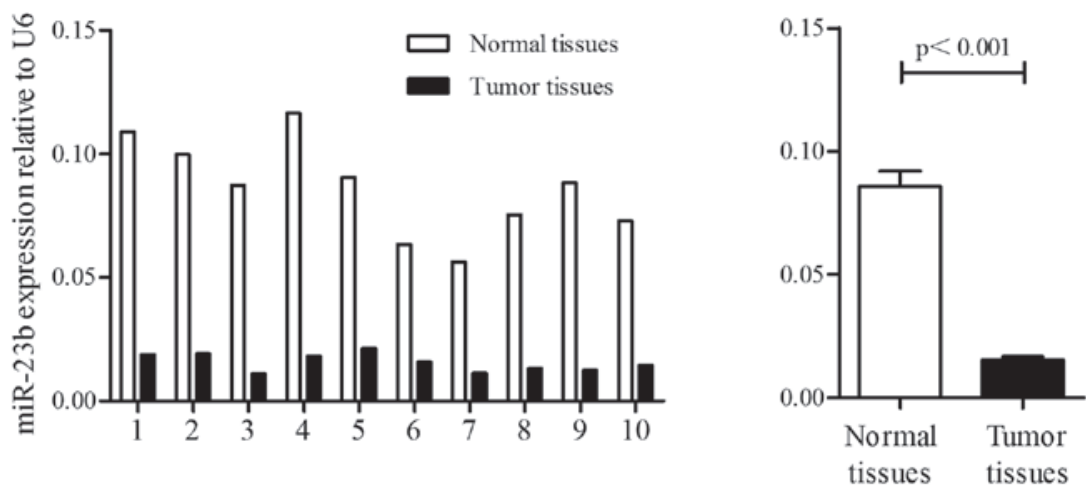

B
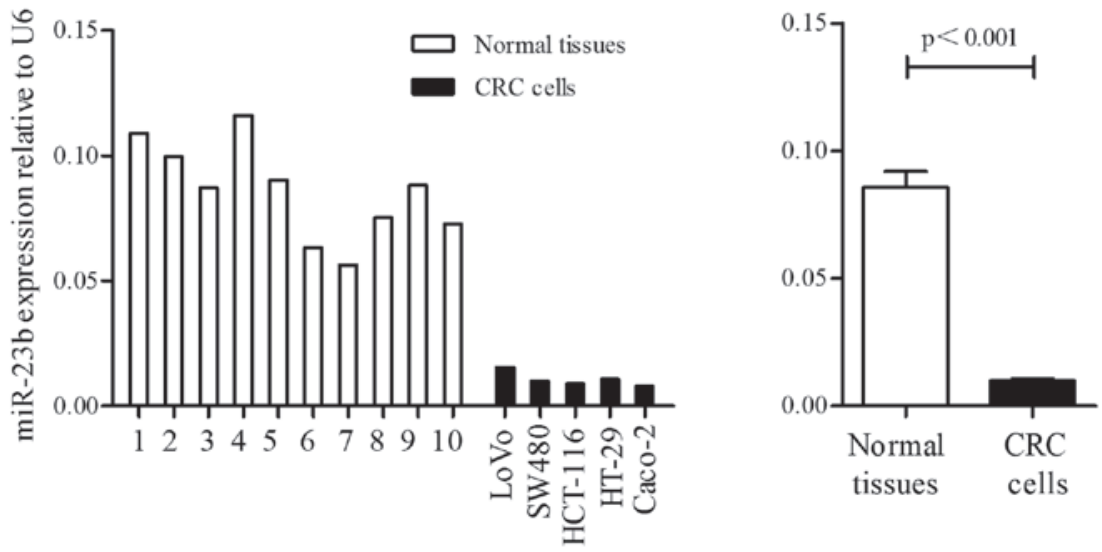

Figure 1. The expression levels of miR-23b in CRC cell lines, primary CRC tissues and adjacent normal tissues. (A) The expression levels of miR-23b were significantly decreased in primary tumor tissues compared with adjacent normal tissues $(\mathrm{P}<0.001)$. (B) The expression levels of miR-23b were significantly decreased in CRC cell lines compared with in non-cancerous colorectal tissues $(\mathrm{P}<0.001)$. CRC, colorectal cancer; miR-23b, microRNA-23b.

Fisher's exact test or $\chi^{2}$ test, as appropriate. The overall survival time was determined as the time between the date of surgery and mortality, and was calculated using the Kaplan-Meier method. Differences between groups were compared using Log-rank test. Cox proportional hazard regression was used to estimate the univariate and multivariate analysis, and calculate hazard ratios (HRs) and 95\% confidence intervals (CIs). All tests were two-tailed, and $\mathrm{P}<0.05$ was considered to indicate a statistically significant difference.

\section{Results}

Expression of miR-23b in primary $C R C$ tissues and $C R C$ cells. To verify previous studies $(24,27)$ that reported downregulation of miR-23b in primary CRC, RT-qPCR was used to evaluate miR-23b expression in 10 paired CRC tissues and adjacent non-cancerous tissues. Additionally, the expression levels of miR-23b in 5 human CRC cell lines, consisting of the LoVo, SW480, HCT-116, HT-29 and Caco-2 cell lines, were also analyzed by RT-qPCR. As shown in Fig. 1A, the miR-23b expression levels were significantly downregulated in CRC tissues compared with non-cancerous tissues $(0.016 \pm 0.004$ vs. $0.086 \pm 0.019 ; \mathrm{P}<0.001)$. The miR-23b expression levels were also significantly decreased in CRC cells compared with non-cancerous tissues (0.010 \pm 0.001 vs. $0.086 \pm 0.019 ; \mathrm{P}<0.001$; Fig. 1B).
Methylation status of $m i R-23 b$ in $C R C$. Since previous studies have described that $\mathrm{miR}-23 \mathrm{~b}$ is an epigenetic target in prostate cancer and glioma stem cells $(16,28)$, the present study examined the methylation status of the miR-23b gene in the LoVo, SW480, HCT-116, HT-29 and Caco-2 cell lines, and two non-malignant colorectal tissue samples. As shown in Fig. 2A, the promoter region of the miR-23b gene was highly methylated in all 5 CRC cell lines, while it was highly unmethylated in non-malignant colorectal tissues. Furthermore, treatment with 5-Aza markedly increased miR-23b expression (Fig. 2B) in the CRC cell lines. These results suggest that promoter methylation has an important role in the downregulation of miR-23b in CRC.

Expression of miR-23b in the plasma of patients with $C R C$. Following validation of $\mathrm{miR}-23 \mathrm{~b}$ expression in paired CRC tissues, the plasma expression level of miR-23b in 96 patients with CRC and 48 healthy control individuals was measured. The relative miR-23b expression level in plasma from patients with CRC was $0.010 \pm 0.009$, which was significantly decreased compared with the healthy control individuals $(0.053 \pm 0.041$; $\mathrm{P}<0.001$; Fig. 3A).

To determine whether miR-23b expression can discriminate between patients with CRC and healthy control individuals, ROC analysis was performed. The optimal cut-off value for sensitivity and specificity was determined based on the highest 
Table I. Association between plasma miR-23b expression and clinicopathological variables in patients with colorectal cancer.

\begin{tabular}{|c|c|c|c|c|}
\hline \multirow[b]{2}{*}{ Variables } & \multirow[b]{2}{*}{ Total, n } & \multicolumn{2}{|c|}{ miR-23b expression, $\mathrm{n}$} & \multirow[b]{2}{*}{ P-value } \\
\hline & & High & Low & \\
\hline Patient number & 96 & 48 & 48 & \\
\hline Gender & & & & 0.826 \\
\hline Female & 29 & 16 & 13 & \\
\hline Male & 67 & 32 & 35 & \\
\hline Age & & & & 0.280 \\
\hline$<60$ years & 45 & 24 & 21 & \\
\hline$\geq 60$ years & 51 & 24 & 27 & \\
\hline Histological type & & & & 0.545 \\
\hline Differentiated & 47 & 22 & 25 & \\
\hline Undifferentiated & 49 & 26 & 23 & \\
\hline TNM stage & & & & 0.007 \\
\hline I, II & 39 & 19 & 20 & \\
\hline III, IV & 57 & 29 & 28 & \\
\hline Tumor depth & & & & 0.041 \\
\hline $\mathrm{T} 1-2$ & 46 & 21 & 25 & \\
\hline T3-4 & 50 & 27 & 23 & \\
\hline Lymph node metastasis & & & & 0.103 \\
\hline No & 44 & 22 & 22 & \\
\hline Yes & 52 & 26 & 26 & \\
\hline Distant metastasis & & & & $<0.001$ \\
\hline No & 73 & 37 & 36 & \\
\hline Yes & 23 & 11 & 12 & \\
\hline Recurrence & & & & $<0.001$ \\
\hline No & 74 & 36 & 38 & \\
\hline Yes & 22 & 12 & 10 & \\
\hline Location & & & & 0.687 \\
\hline Rectum & 46 & 24 & 22 & \\
\hline Colon & 50 & 24 & 26 & \\
\hline
\end{tabular}

P-values $<0.05$ are presented in bold. miR-23b, microRNA-23b; TNM, tumor-node-metastasis.

Youden's Index in ROC curve analysis. The area under the ROC curve (AUC) of 0.842 (sensitivity, $84.38 \%$; specificity, 77.08\%; 95\% CI, 0.763-0.922) indicated that miR-23b expression can discriminate between patients with CRC and healthy control individuals (Fig. 3B).

Association between the plasma miR-23b levels and the clinicopathological variables. The median value (0.007) of miR-23b expression in all CRC plasma samples, measured by RT-qPCR, was used as a threshold point to classify 96 patients into high- and low-miR-23b expression groups. The association between the plasma miR-23b expression level and the clinicopathological parameters of the patients with CRC is shown in Table I. The present results revealed that the miR-23b expression levels in the plasma of patients with CRC were not significantly associated with gender, age, histological type, lymph node metastasis or tumor location. The associations between the miR-23b expression level in the plasma and TNM stage $(\mathrm{P}=0.007)$, tumor depth $(\mathrm{P}=0.041)$, distant metastasis $(\mathrm{P}<0.001)$ and recurrence $(\mathrm{P}<0.001)$ were all statistically significant.

Expression of plasma miR-23b and prognosis. To determine whether miR-23b has prognostic significance, Kaplan-Meier survival analysis and Cox proportional hazard analysis were performed. As shown in Fig. 4, Kaplan-Meier analysis showed that the high miR-23b group had a significantly increased overall survival rate compared with the low miR-23b group $(\mathrm{P}=0.005$; Fig. 4A). In addition, CRC patients with a high miR-23b level in plasma had a longer recurrence-free survival time compared with the low miR-23b patients $(\mathrm{P}=0.002$; Fig. 4B).

The association between clinicopathological parameters and expression level of miR-23b with the clinical outcome was also analyzed in patients with CRC. The Cox proportional hazard regression analysis showed that of age $>60$ years $(\mathrm{P}=0.005)$, increased TNM stage $(\mathrm{P}<0.001)$, increased tumor depth $(\mathrm{P}=0.001)$, presence of lymph node metastasis $(\mathrm{P}=0.007)$ 
Table II. Univariate and multivariate analysis for overall survival of patients with colorectal cancer.

\begin{tabular}{|c|c|c|c|c|c|c|}
\hline \multirow[b]{2}{*}{ Parameters } & \multicolumn{3}{|c|}{ Univariate } & \multicolumn{3}{|c|}{ Multivariate } \\
\hline & HR & $95 \% \mathrm{CI}$ & P-value & HR & $95 \% \mathrm{CI}$ & P-value \\
\hline Gender (female/male) & 1.520 & $0.816-2.834$ & 0.187 & & & \\
\hline Age $(<60$ years $/ \geq 60$ years $)$ & 2.499 & $1.312-4.763$ & 0.005 & 3.305 & $1.628-6.709$ & 0.001 \\
\hline Histological type (differentiated/undifferentiated) & 1.489 & $0.875-2.535$ & 0.142 & & & \\
\hline TNM stage (I, II/III, IV) & 3.047 & $1.630-5.697$ & $<0.001$ & & & \\
\hline Tumor depth (T1-2/T3-4) & 2.525 & $1.434-4.447$ & 0.001 & & & \\
\hline Lymph node metastasis (no/yes) & 2.179 & $1.237-3.839$ & 0.007 & & & \\
\hline Distant metastasis (no/yes) & 9.356 & 5.214-16.792 & $<0.001$ & 13.277 & $6.844-25.758$ & $<0.001$ \\
\hline Recurrence (no/yes) & 1.293 & $0.721-2.318$ & 0.389 & & & \\
\hline Location (rectum/colon) & 1.396 & $0.819-2.382$ & 0.220 & & & \\
\hline miR-23b expression (low/high) & 2.447 & $1.392-4.301$ & 0.002 & & & \\
\hline
\end{tabular}

HR, hazard ratio; CI, confidence interval; TNM, tumor-node-metastasis; miR-23b, microRNA-23b.

A

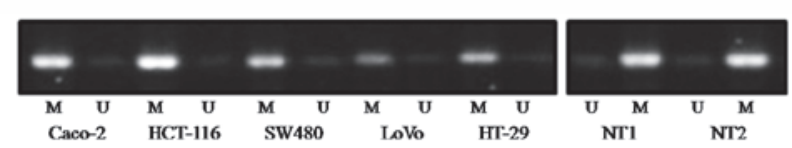

B

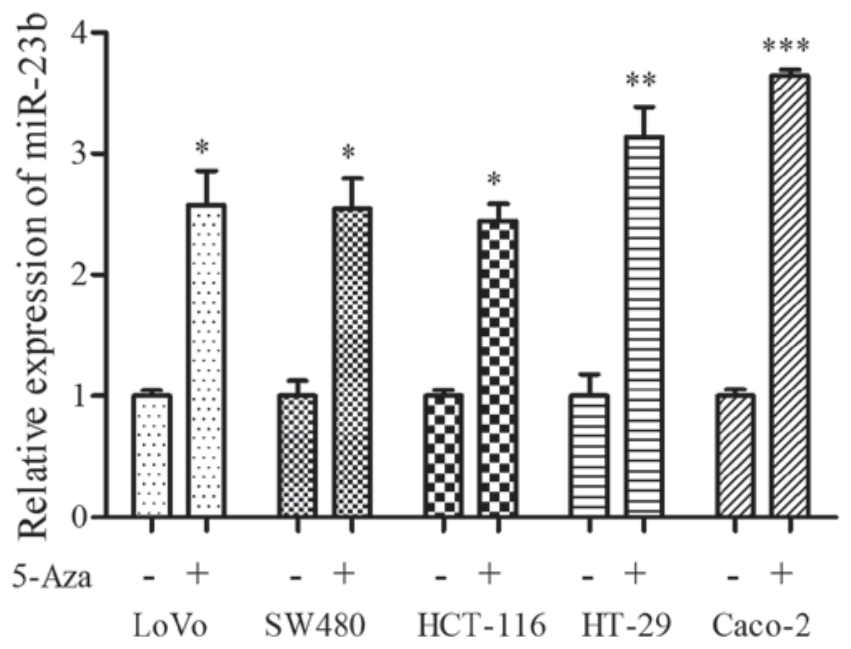

Figure 2. Methylation status of miR-23b promoter in CRC cells. (A) Methylation-specific PCR of miR-23b in CRC cells and non-cancerous colorectal tissues. (B) Reverse transcription-quantitative PCR analysis of miR-23b expression subsequent to $5 \mu \mathrm{M} 5$-Aza treatment for $72 \mathrm{~h}$. ${ }^{*} \mathrm{P}<0.05$; ${ }^{* *} \mathrm{P}<0.01 ;{ }^{* * *} \mathrm{P}<0.001$. miR-23b, microRNA-23b; CRC, colorectal cancer; PCR, polymerase chain reaction; 5-AZA, 5-aza-2-deoxycytidine 5-aza-2-deoxycytidine; M, methylated; U, unmethylated; NT, non-cancerous tissue.

and distant metastasis $(\mathrm{P}<0.001)$ were significant prognositic factors (Table II). The low expression level of miR-23b was associated with a relative risk of death of $2.447(95 \% \mathrm{CI}$, 1.392-4.301; $\mathrm{P}=0.002$ ).

Multivariate analysis was performed using age, TNM stage, tumor depth, lymph node metastasis, distant metastasis and the expression level of miR-23b. These data revealed that only age >60 years old (HR, 3.305; 95\% CI, 1.628-6.709; $\mathrm{P}=0.001)$ and presence of distant metastasis (HR, 13.277; 95\%
CI, 6.844-25.758; $\mathrm{P}<0.001)$ were independently associated with a significantly increased risk of mortality (Table II). The expression level of miR-23b in the plasma of CRC patients was not a significant independent risk factor.

\section{Discussion}

In previous years, studies have demonstrated that detecting levels of plasma miRNAs in the blood is viable for clinical application (13-15). Measurement of tumor-derived miRNAs in the plasma is an important approach for the blood-based detection of human cancer (12). Numerous studies have indicated that plasma miRNAs have potential diagnostic or prognostic value in various types of tumors, including breast cancer (14), leukemia (29), gastric cancer (30), oral cancer (31) and colon cancer (32).

miR-23b has been demonstrated to be involved in several tumor-associated biological process, particularly in tumor metastasis. For example, overexpression of miR-23b has been shown to inhibit migration in prostate cancer cells $(16,33)$, and hepatocellular carcinoma cells (17). In glioma, overexpression of miR-23b significantly inhibited cell migration and invasion while inhibition of miR-23b expression significantly increased migration (18). Increased expression of miR-23b also inhibited proliferation in prostate cancer (16), epithelial ovarian cancer (19), and hepatocellular carcinoma, where it acts as a tumor suppressor by targeting the urokinase-type plasminogen activator and c-met (17). In addition, miR-23b functions as a regulator for G0-G1 cell-cycle arrest $(16,34)$. miR-23b was also found to regulate transforming growth factor- $\beta$ /bone morphogenetic protein signaling and affected liver stem cell differentiation (35). In colon cancer, Zhang et al demonstrated that miR-23b is downregulated in human colon cancer and mediates multiple steps of metastasis, including tumor growth, invasion and angiogenesis (24). Therefore, it was hypothesized that quantitative measuring of miR-23b in the plasma may be a promising biomarker in CRC patients.

Firstly, the expression level of miR-23b in CRC cells and paired tissues from CRC patients was validated. A significantly 
A

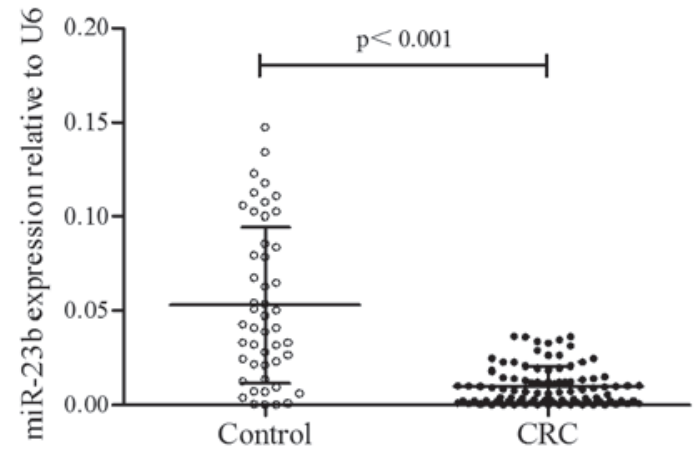

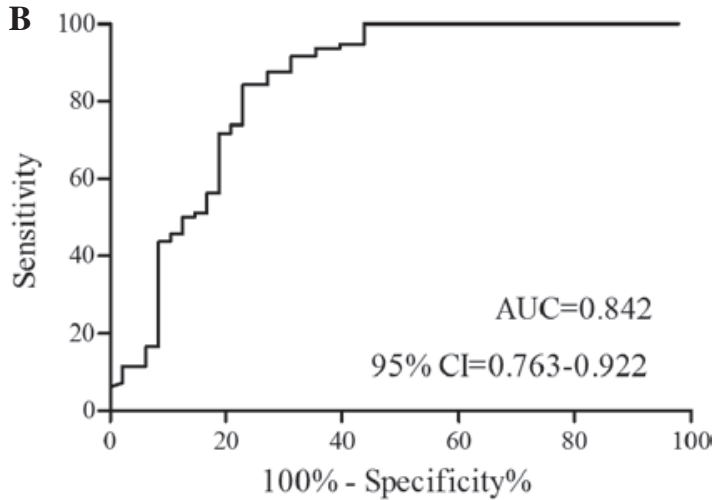

Figure 3. miR-23b expression levels in plasma samples from patients with CRC and healthy controls. Data are shown as the mean \pm standard deviation of experiments. (A) miR-23b expression levels in plasma were significantly downregulated in CRC patients compared with healthy controls (P<0.001). (B) Receiver operating characteristic analysis showing the ability of the miR-23b level in plasma to discriminate between CRC patients and healthy controls. miR-23b, microRNA-23b; CRC, colorectal cancer; AUC, area under the curve; CI, confidence interval.

A

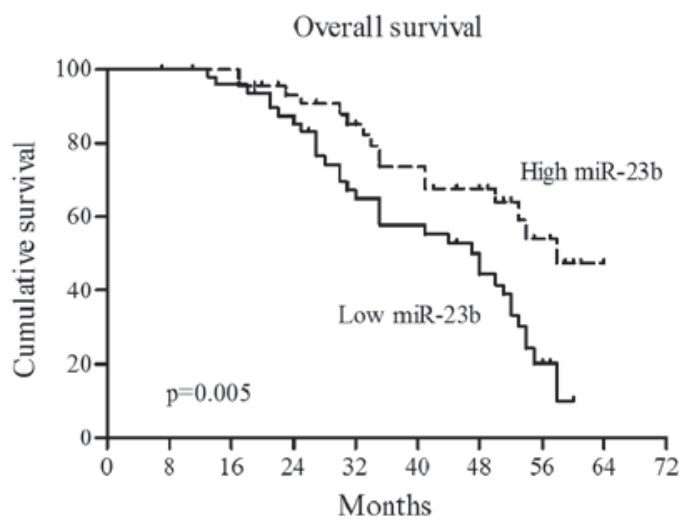

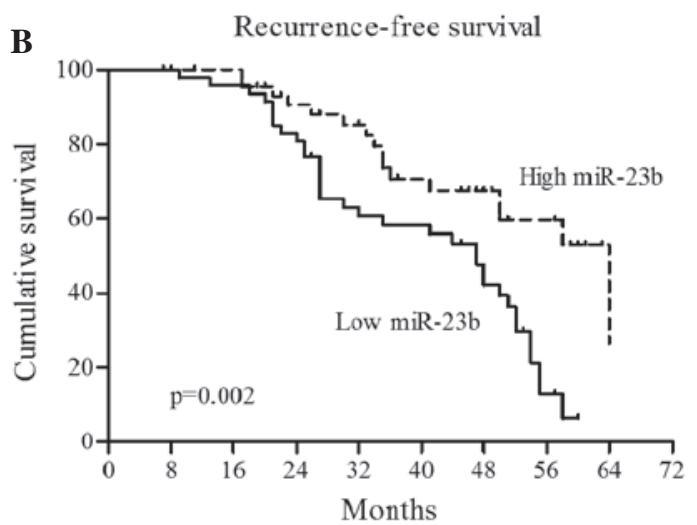

Figure 4. Survival analysis of patients with CRC with high or low miR-23b expression in the plasma. (A) CRC patients with a high miR-23b level had an improved overall survival rate $(\mathrm{P}=0.005)$. (B) $\mathrm{CRC}$ patients with high miR-23b expression showed a longer recurrence-free survival time $(\mathrm{P}=0.02)$. miR-23b, microRNA-23b; CRC, colorectal cancer.

decreased expression level of miR-23b was found in CRC cells and malignant tissues compared with non-malignant tissues. Similarly, several studies have demonstrated that miR-23b expression is significantly downregulated in various types of tumor, including prostate, hepatocellular, bladder, endometrial carcinosarcoma and colon cancer (16,17,20-24). Conversely, miR-23b is overexpressed in oral squamous cell carcinoma (36), glioma (37) and breast cancer $(38,39)$. Tissue specificity may be the reason of differential expression of miR-23b in cancers. Additionally, considering promoter methylation plays a role in the downregulation of miR-23b in prostate cancer (16), the MSP method was applied to analyze the methylation status of miR-23b in CRC. miR-23b was highly methylated in CRC cells, but it was unmethylated in non-malignant tissues. To further analyze whether methylation of the miR-23b promoter regulates its expression, cancer cell lines were treated with the demethylating agent 5-Aza. Subsequent to 5-Aza treatment, miR-23b expression was significantly upregulated in all 5 cell lines. These results indicate that methylation of the miR-23b promoter directly regulates its transcriptional repression in CRC cells.

RT-qPCR demonstrated that miR-23b was significantly downregulated in plasma from CRC patients compared with healthy controls. Based on the ROC curve analysis, the plasma level of miR-23b had a clinically satisfactory degree of specificity and sensitivity with an AUC of 0.842, suggesting that miR-23b expression can discriminate CRC from healthy controls and potentially be used as a diagnostic marker for CRC. In addition to the present study, miR-23b expression also distinguishes between normal and bladder cancer tissues with an AUC of 0.885 (16). The diagnostic value of plasma miR-23b for cancer requires additional study in a large trial. The present findings revealed that the miR-23b expression in plasma was significantly associated with TNM stage, tumor depth, distant metastasis and tumor recurrence. Similarly, low miR-23b expression associates with the development of metastases in breast cancer (40) and colon cancer lung metastasis (24). Low expression of miR-23b in plasma was significantly associated with poor overall survival and shorter recurrence-free survival in CRC patients. These results were consistent with previous studies of bladder cancer (16), ovarian cancer (19) and prostate cancer (21). Therefore, miR-23b may potentially be a powerful prognostic marker for cancer patients.

In conclusion, miR-23b is epigenetically downregulated in $\mathrm{CRC}$ and the present data suggest a potential diagnostic and prognostic value of plasma miR-23b levels in discriminating between patients with malignancy and healthy individuals, and also for predicting overall survival for patients with CRC. 


\section{References}

1. Siegel R, Desantis C and Jemal A: Colorectal cancer statistics, 2014. CA Cancer J Clin 64: 104-117, 2014.

2. Wan DS: Epidemiologic trend of and strategies for colorectal cancer. Ai Zheng 28: 897-902, 2009 (In Chinese).

3. van Dam J, Friedman LS: Missed cancers at colonscopy: Learning the hard way. Gastrointest Endosc 45: 530-533, 1997.

4. He L and Hannon GJ: MicroRNAs: Small RNAs with a big role in gene regulation. Nat Rev Genet 5: 522-531, 2004.

5. Chen K and Rajewsky N: The evolution of gene regulation by transcription factors and microRNAs. Nat Rev Genet 8: 93-103, 2007.

6. Bhaumik D, Scott GK, Schokrpur S, Patil CK, Campisi J and Benz CC: Expression of microRNA-146 suppresses NF-kappaB activity with reduction of metastatic potential in breast cancer cells. Oncogene 27: 5643-5647, 2008.

7. Abella V, Valladares M, Rodriguez T, Haz M, Blanco M, Tarrío N Iglesias P, Aparicio LA and Figueroa A: MiR-203 regulates cell proliferation through its influence on Hakai expression. PLoS One 7: e52568, 2012.

8. Li J, Huang H, Sun L, Yang M, Pan C, Chen W, Wu D, Lin Z, Zeng C, Yao Y, et al: MiR-21 indicates poor prognosis in tongue squamous cell carcinomas as an apoptosis inhibitor. Clin Cancer Res 15: 3998-4008, 2009.

9. Lanza G, Ferracin M, Gafà R, Veronese A, Spizzo R, Pichiorri F Liu CG, Calin GA, Croce CM and Negrini M: Mrna/MicroRNAs gene expression profile in microsatellite unstable colorectal cancer. Mol Cancer 6: 54, 2007.

10. Link A, Balaguer F, Shen Y, Nagasaka T, Lozano JJ, Boland CR and Goel A: Fecal MicroRNAs as novel biomarkers for colon cancer screening. Cancer Epidemiol Biomarkers Prev 19: 1766-1774, 2010.

11. Asangani IA, Rasheed SA, Nikolova DA, Leupold JH, Colburn NH, Post S and Allgayer H: Microrna-21 (mir-21) post-transcriptionally downregulates tumor suppressor pdcd 4 and stimulates invasion, intravasation and metastasis in colorectal cancer. Oncogene 27: 2128-2136, 2008.

12. Mitchell PS, Parkin RK, Kroh EM, Fritz BR, Wyman SK, Pogosova-Agadjanyan EL, Peterson A, Noteboom J, O'Briant KC, Allen A, et al: Circulating microRNAs as stable blood-based markers for cancer detection. Proc Natl Acad Sci USA 105: 10513-10518, 2008.

13. Gilad S, Meiri E, Yogev Y, Benjamin S, Lebanony D, Yerushalmi N, Benjamin H, Kushnir M, Cholakh H, Melamed N, et al: Serum microRNAs are promising novel biomarkers. PLoS One 3: e3148, 2008.

14. Schrauder MG, Strick R, Schulz-Wendtland R, Strissel PL, Kahmann L, Loehberg CR, Lux MP, Jud SM, Hartmann A, Hein A, et al: Circulating micro-RNAs as potential blood-based markers for early stage breast cancer detection. PLoS One 7: e29770, 2012.

15. Ng EK, Chong WW, Jin H, Lam EK, Shin VY, Yu J, Poon TC, Ng SS and Sung JJ: Differential expression of microRNAs in plasma of patients with colorectal cancer: A potential marker for colorectal cancer screening. Gut 58: 1375-1381, 2009.

16. Majid S, Dar AA, Saini S, Arora S, Shahryari V, Zaman MS, Chang I, Yamamura S, Tanaka Y, Deng G and Dahiya R: MiR-23b represses proto-oncogene Src kinase and functions as methylation-silenced tumor suppressor with diagnostic and prognostic significance in prostate cancer. Cancer Res 72: 6435-6446, 2012.

17. Salvi A, Sabelli C, Moncini S, Venturin M, Arici B, Riva P, Portolani N, Giulini SM, De Petro G and Barlati S: MicroRNA-23b mediates urokinase and c-met downmodulation and a decreased migration of human hepatocellular carcinoma cells. FEBS J 276 2966-2982, 2009.

18. Loftus JC, Ross JT, Paquette KM, Paulino VM, Nasser S, Yang Z, Kloss J, Kim S, Berens ME and Tran NL: MiRNA expression profiling in migrating glioblastoma cells: Regulation of cell migration and invasion by miR- $23 \mathrm{~b}$ via targeting of Pyk2. PLoS One 7: e39818, 2012.

19. Li W, Liu Z, Chen L, Zhou L and Yao Y: MicroRNA-23b is an independent prognostic marker and suppresses ovarian cancer progression by targeting runt-related transcription factor- 2 . FEBS Lett 588: 1608-1615, 2014

20. Tong AW, Fulgham P, Jay C, Chen P, Khalil I, Liu S, Senzer N, Eklund AC, Han J and Nemunaitis J: MicroRNA profile analysis of human prostate cancers. Cancer Gene Ther 16: 206-216, 2009.
21. Goto Y, Kojima S, Nishikawa R, Enokida H, Chiyomaru T, Kinoshita T, Nakagawa M, Naya Y, Ichikawa T and Seki N: The microRNA-23b/27b/24-1 cluster is a disease progression marker and tumor suppressor in prostate cancer. Oncotarget 5: 7748-7759, 2014.

22. Sun T, Yang M, Chen S, Balk S, Pomerantz M, Hsieh CL, Brown M, Lee GS and Kantoff PW: The altered expression of MiR-221/-222 and MiR-23b/-27b is associated with the development of human castration resistant prostate cancer. Prostate 72: 1093-1103, 2012.

23. Castilla MÁ, Moreno-Bueno G, Romero-Pérez L, Van De Vijver K, Biscuola M, López-García MÁ, Prat J, Matías-Guiu X, Cano A, Oliva E and Palacios J: Micro-RNA signature of the epithelial-mesenchymal transition in endometrial carcinosarcoma. J Pathol 223: 72-80, 2011

24. Zhang H, Hao Y, Yang J, Zhou Y, Li J, Yin S, Sun C, Ma M, Huang Y and Xi JJ: Genome-wide functional screening of miR-23b as a pleiotropic modulator suppressing cancer metastasis. Nat Commun 2: 554, 2011.

25. Obrocea FL, Sajin M, Marinescu EC and Stoica D: Colorectal cancer and the 7th revision of the TNM staging system: Review of changes and suggestions for uniform pathologic reporting. Rom J Morphol Embryol 52: 537-544, 2011.

26. Livak KJ and Schmittgen TD: Analysis of relative gene expression data using real-time quantitative PCR and the $2^{-\Delta \Delta C T}$ method. Methods 25: 402-408, 2001

27. Zhou X, Xu X, Wang J, Lin J and Chen W: dentifying miRNA/ mRNA negative regulation pairs in colorectal cancer. Sci Rep 5: $12995,2015$.

28. Geng J, Luo $\mathrm{H}, \mathrm{Pu} \mathrm{Y,} \mathrm{Zhou} \mathrm{Z,} \mathrm{Wu} \mathrm{X,} \mathrm{Xu} \mathrm{W,} \mathrm{and} \mathrm{Yang} \mathrm{Z:}$ Methylation mediated silencing of miR-23b expression and its role in glioma stem cells. Neurosci Lett 528: 185-189, 2012.

29. Tanaka M, Oikawa K, Takanashi M, Kudo M, Ohyashiki J, Ohyashiki K and Kuroda M: Down-regulation of miR-92 in human plasma is a novel marker for acute leukemia patients. PLoS One 4: e5532, 2009.

30. Tsujiura M, Ichikawa D, Komatsu S, Shiozaki A, Takeshita H, Kosuga T, Konishi H, Morimura R, Deguchi K, Fujiwara H, et al: Circulating microRNAs in plasma of patients with gastric cancers. Br J Cancer 102: 1174-1179, 2010.

31. Liu CJ, Kao SY, Tu HF, Tsai MM, Chang KW and Lin SC: Increase of microRNA miR-31 level in plasma could be a potential marker of oral cancer. Oral Dis 16: 360-364, 2010

32. Cheng $\mathrm{H}$, Zhang L, Cogdell DE, Zheng $\mathrm{H}$, Schetter AJ, Nykter M, Harris CC, Chen K, Hamilton SR and Zhang W: Circulating plasma MiR-141 is a novel biomarker for metastatic colon cancer and predicts poor prognosis. PLoS One 6: e17745, 2011

33. Ishteiwy RA, Ward TM, Dykxhoorn DM and Burnstein KL: The microRNA -23b/-27b cluster suppresses the metastatic phenotype of castration-resistant prostate cancer cells. PLoS One 7: e52106, 2012.

34. Wang KC, Garmire LX, Young A, Nguyen P, Trinh A, Subramaniam S, Wang N, Shyy JY, Li YS and Chien S: Role of microRNA-23b in flow-regulation of Rb phosphorylation and endothelial cell growth. Proc Natl Acad Sci USA 107: 3234-3239, 2010.

35. Rogler CE, Levoci L, Ader T, Massimi A, Tchaikovskaya T, Norel R and Rogler LE: MicroRNA-23b cluster microRNAs regulate transforming growth factor-beta/bone morphogenetic protein signaling and liver stem cell differentiation by targeting smads. Hepatology 50: 575-584, 2009.

36. Scapoli L, Palmieri A, Lo Muzio L, Pezzetti F, Rubini C, Girardi A, Farinella F, Mazzotta M and Carinci F: MicroRNA expression profiling of oral carcinoma identifies new markers of tumor progression. Int J Immunopathol Pharmacol 23: 1229-1234, 2010.

37. Chen L, Han L, Zhang K, Shi Z, Zhang J, Zhang A, Wang Y, Song Y, Li Y, Jiang T, et al: VHL regulates the effects of miR-23b on glioma survival and invasion via suppression of HIF-1 $\alpha /$ VEGF and $\beta$-catenin/Tcf-4 signaling. Neuro Oncol 14: 1026-1036, 2012.

38. Paris O, Ferraro L, Grober OM, Ravo M, De Filippo MR, Giurato G, Nassa G, Tarallo R, et al: Direct regulation of microRNA biogenesis and expression by estrogen receptor beta in hormone-responsive breast cancer. Oncogene 31: 4196-4206, 2012.

39. Jin L, Wessely O, Marcusson EG, Ivan C, Calin GA and Alahari SK: Prooncogenic factors miR-23b and miR-27b are regulated by Her $2 / \mathrm{Neu}, \mathrm{EGF}$, and TNF- $\alpha$ in breast cancer. Cancer Res 73: 2884-2896, 2013

40. Pellegrino L, Stebbing J, Braga VM, Frampton AE, Jacob J, Buluwela L, Jiao LR, Periyasamy M, Madsen CD, Caley MP, et al: MiR-23b regulates cytoskeletal remodeling, motility and metastasis by directly targeting multiple transcripts. Nucleic Acids Res 41: 5400-5412,2013. 